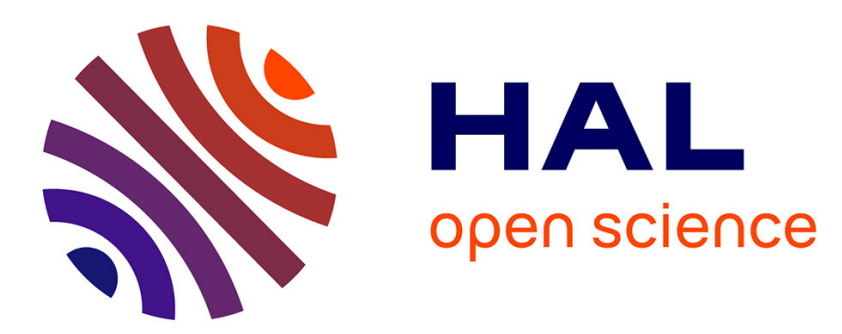

\title{
Executive deficits in schizophrenia: mediation by processing speed and its relationships with aging
}

Flavien Thuaire, Fabien Rondepierre, Guillaume T. Vallet, Isabelle Jalenques, Marie Izaute

\section{- To cite this version:}

Flavien Thuaire, Fabien Rondepierre, Guillaume T. Vallet, Isabelle Jalenques, Marie Izaute. Executive deficits in schizophrenia: mediation by processing speed and its relationships with aging. Psychological Medicine, 2020, pp.1-9. 10.1017/S0033291720002871 . hal-02978614

\section{HAL Id: hal-02978614 https://hal.science/hal-02978614}

Submitted on 4 Nov 2020

HAL is a multi-disciplinary open access archive for the deposit and dissemination of scientific research documents, whether they are published or not. The documents may come from teaching and research institutions in France or abroad, or from public or private research centers.
L'archive ouverte pluridisciplinaire HAL, est destinée au dépôt et à la diffusion de documents scientifiques de niveau recherche, publiés ou non, émanant des établissements d'enseignement et de recherche français ou étrangers, des laboratoires publics ou privés. 
1 Executive deficits in schizophrenia: Mediation by processing speed and its relationships with aging

4 Authors and affiliations.

5 Flavien Thuaire ${ }^{\mathrm{a}}$, Fabien Rondepierre ${ }^{\mathrm{b}}$, Guillaume T. Vallet ${ }^{\mathrm{a}}$, Isabelle Jalenques ${ }^{\mathrm{c}}$, Marie 6 Izaute $^{\mathrm{a}^{*}}$

7

8

${ }^{a}$ Université Clermont Auvergne, CNRS, LAPSCO, 34 avenue Carnot - TSA 60401 - 63001 Clermont-Ferrand Cedex 1.

${ }^{\mathrm{b}}$ Service de Psychiatrie de 1'Adulte A et Psychologie Médicale, Centre Mémoire de Ressources et de Recherche, CHU Clermont-Ferrand, Clermont-Ferrand, France.

${ }^{\mathrm{c}}$ Service de Psychiatrie de l'Adulte A et Psychologie Médicale, Centre Mémoire de Ressources et de Recherche, CHU Clermont-Ferrand, Institut de Psychiatrie-GDR 3557, Université Clermont Auvergne, Clermont-Ferrand, France.

${ }^{*}$ Corresponding author: Marie Izaute LAPSCO, UMR CNRS 6024, 34 avenue Carnot - TSA 60401 - 63001 Clermont-Ferrand Cedex 1. France.

Telephone: + 33473406255 - Fax: + 33473406482

E-mail: marie.izaute@uca.fr 


\section{Abstract}

Background: Executive deficits are a core characteristic of schizophrenia. Yet, the origin of these impairments remains unclear as they may be caused by processing slowing. This issue is of particular interest for aging insofar as cognitive aging is also associated with decline in executive functioning and a slowing of processing speed. As schizophrenia patients' life expectancy increases, a better understanding of the origin of older patients' cognitive deficits becomes essential so that healthcare can be adapted to suit them. This study aims to determine whether processing speed mediates how schizophrenia affects executive functions, and whether these relationships are moderated by age.

Methods: Sixty-two schizophrenia patients (27 women) and 62 healthy comparison subjects matched for age (range: 18 to 76 years), gender and education performed neurocognitive tests to evaluate their executive functions (shifting, updating, inhibition and access) and processing speed.

Results: Processing speed mediated the effect of schizophrenia on the four specific executive functions, and age moderated this mediation for shifting, updating and access, but in different ways. Age moderated the effect of processing speed on shifting, the direct effect of schizophrenia on access, and both the effect of processing speed and direct effect of schizophrenia on updating.

Conclusions: This research highlights the need to evaluate processing speed routinely during therapeutic follow-up, as it is easy and simple to assess and appears to be at the heart of the cognitive deficits in schizophrenia. Finally, processing speed abilities yield information about the evolution of cognition with aging in schizophrenia.

Key Words: Schizophrenia; Adulthood; Aging; Processing speed; Executive functions; Miyake's model. 


\section{Introduction}

Cognitive impairment is a core feature of schizophrenia and affects most cognitive domains (Heinrichs \& Zakzanis, 1998; Mesholam-Gately et al., 2009). Deficits appeared even before the onset of schizophrenia (Meier et al., 2014) and patients' decline in later life is strongly related to their functional competences (Harvey et al., 1999; Kalache et al., 2015). An important issue in the study of schizophrenia is that both executive functions (EFs) (Reichenberg \& Harvey, 2007) and processing speed (PS) (Dickinson et al., 2007) are impaired, and that these deficits may affect other cognitive abilities. However, despite the increase in schizophrenia patients' life expectancy (Cohen et al., 2008; E. E. Lee et al., 2018), the course of cognitive impairment in late adulthood remains unclear owing to the lack of studies that investigate this particular issue (Herold et al., 2017; Rajji \& Mulsant, 2008), and because normal aging is also associated with cognitive decline (Cona et al., 2013; Verhaeghen \& Cerella, 2002). However, knowledge is crucial for adapting treatments and cognitive remediation to older schizophrenia patients. Given that remediation programs are currently better suited to younger patients, they need to be adapted to the specificity of older patients (Wykes et al., 2009).

EFs allow adapting behavior to diverse situations (e.g. creating a plan, initiating its execution, persevering until completion). They also mediate our ability to organize our thoughts in a targeted manner (Jurado \& Rosselli, 2007). In other words, they are regarded as higher order cognitive processes supporting other areas of cognition and thus are widely used in everyday life. Although executive functioning covers broad concepts, the importance of considering some specific EFs is now well established. The common distinction proposed identifies three specific EFs, namely shifting, updating and inhibition (Miyake et al., 2000). Subsequently, Fisk \& Sharp (2004) identified a fourth function, referred to as "access", which reflects the efficiency of access to long-term memory and may be assessed with word fluency tests. 
Executive deficits in schizophrenia are well established (Fioravanti et al., 2012). A more finegrained analysis of these deficits revealed impairments in shifting, updating and inhibition (Chan et al., 2006; Donohoe et al., 2006; Rabanea-Souza et al., 2016; Raffard \& Bayard, 2012; Wongupparaj et al., 2015) as well as access (Rossell, 2006), even though there were some discrepancies concerning inhibition (Chan et al., 2010; Laurenson et al., 2015; Thuaire et al., 2020; Westerhausen et al., 2011). Importantly, insofar as EFs are strongly linked to everyday life skills (McClure et al., 2007) and quality of life (Tolman \& Kurtz, 2012) in schizophrenia, they are an important target area for cognitive remediation (Penadés et al., 2010).

Nevertheless, it remains unclear whether executive impairment in schizophrenia comes from an executive impairment per se or from low-order processes instead. Contrary to executive functioning, which is thought to be uniquely human (Luria, 1966) or at least specific to the most intelligent species, lower-order processes are less evolved as cognitive functions. Those such as PS are implicated in almost every cognitive process. Thus, complex operations need to process simple operations quickly in order to keep their product available (Salthouse, 1996). Consequently, PS and EFs share some mutual variance (Albinet et al., 2012) but tap into different processes. Indeed, some authors suggested that PS is be the most important deficit in patients (Dickinson et al., 2007) and may mediate EFs impairments (Rodríguez-sánchez et al., 2007). Accordingly, it was shown in schizophrenia that PS contributed significantly to executive functioning (Raffard \& Bayard, 2012), even when the executive tests used were not time-constrained (Ojeda et al., 2012). Yet, it is worth mentioning that PS does not account for all the deficits in EFs (Neill \& Rossell, 2013), and its statistical control does not cancel out the deficits in all measures of EFs (Savla et al., 2011). Thus, the relationships between PS and EFs may be very complex, as PS seems to mediate some executive deficits, although the analyses conducted in previous studies were not designed as accurate tests for mediation. Moreover, as both EFs and PS declined severely in healthy aging and appear to play a distinctive role in 
explaining age-related deficits (Albinet et al., 2012; T. Lee et al., 2012), we surmised that participants' age would be a good criterion for supplementing our knowledge about this mediation.

Indeed, as EFs and PS are both impaired in healthy aging and in schizophrenia, some studies looked at whether these processes would show accelerated aging. Accelerated aging means that age effects would be greater in patients than in healthy participants. Some of the studies which examined this question in terms of executive functioning concluded in favor of the existence of accelerated aging (Fucetola et al., 2000; Herold et al., 2017), while others did not (Irani et al., 2011; Loewenstein et al., 2012; Stirling et al., 2003). To shed some light on these controversial results, in a previous article our team analyzed the performances of young, middle-aged and older schizophrenia patients and healthy comparison participants in neuropsychological tests assessing the four specific EFs (Thuaire et al., 2020). The results showed that accelerated aging was observed for shifting, and that access was impaired in older schizophrenia patients. However, updating and inhibition were not more affected by the pathology with aging. Similarly, studies about the effects of accelerated aging on PS in schizophrenia are conflicting. One study found accelerated aging in Trail-Making-Test Part A (TMT-A) and digit symbol (Loewenstein et al., 2012), whereas another found it in TMT-A but not digit symbol (Bowie et al., 2008), and a third study showed no accelerated aging in TMT-A (Herold et al., 2017). It is therefore not clear from the literature whether aging increases executive deficits and/or the cognitive slowing of schizophrenia patients in comparison to healthy participants. In light of the results of our previous work (Thuaire et al., 2020) and studies showing a link between PS and EFs performance (Neill \& Rossell, 2013; Raffard \& Bayard, 2012; Savla et al., 2011), one possibility might be that PS mediates some EFs and that such mediation may have different strengths according to specific EFs. Moreover, aging may have different effects on this mediation as a function of specific EFs. 
Thus, we set out to analyze our previous study further to determine which specific EFs are strongly mediated by PS because such knowledge will help remediation programs target the root causes of the executive deficits. We hypothesized that PS would mediate the four specific EFs but with different strengths. Moreover, we wanted to ascertain whether age could be a moderator of these mediation effects in order to help adapt remediation programs to strengths and weaknesses specific to older patients. According to our previous study showing increased deficits in older patients for shifting and access (Thuaire et al., 2020), we surmised that age would moderate this mediation only for these functions. This result lends further weight to the arguments in support of the specificity of schizophrenia aging and the need to adapt remediation programs to older patients (Wykes et al., 2009).

\section{Methods and material}

\section{Participants}

The present study involves the same participants as those recruited and described in our previous study (Thuaire et al., 2020).

This study was conducted in accordance with ethical standards and with the approval of the local ethics committees (EudraCT 2010-A00857-32 and PRI 2000, HUS N²326). Before the investigation started, and after receiving a full explanation about the study, all the participants gave their informed consent in writing. They were 62 clinically-stable outpatients with schizophrenia recruited from the Psychiatric Departments of the University Hospitals. Patients with any current co-morbid neurologic or psychiatric disorder, including alcohol or substance abuse or dependence, were not included. Their psychiatric symptoms were assessed according to the Positive And Negative Symptoms Scale (PANSS, Kay et al. 1987). They were screened for anxiety and depression using the Hospital Anxiety and Depression Scale (HADS, Zigmond \& Snaith 1983). Verbal intelligence quotient (IQ) was evaluated using vocabulary and 
arithmetic tests taken from the Wechsler Adult Intelligence Scale, revised (WAIS-R, Silverstein 1982). Patients received stable doses of psychotropic medication for at least 4 weeks. In addition, 62 healthy comparison participants matching the patients in terms of age, gender and education were recruited from the community. None of these participants had a known neurological or psychiatric affliction or was currently suffering or had suffered in the past from alcohol or substance abuse or dependence. The age of the participants ranged from 18 to 76 years.

Table 1 presents the demographical, clinical and descriptive statistics of the group comparison data.

\section{Material}

EFs were assessed according to the framework proposed by Miyake et al. (2000), which distinguishes three specific EFs (shifting, updating and inhibition), with the addition of Fisk and Sharp (2004) for efficiency of access to long-term memory. Two tests were used for each specific function, and a further two tests were also used to assess PS. See the supplement for a more detailed description of the tests.

The scores used in the analyses consisted of:

Shifting tasks:

Plus-minus task(Jersild, 1927; Spector \& Biederman, 1976): Participants had to switch between adding and subtracting 3 in respect of different numbers. The shift cost was calculated as the difference between the time taken to complete the third list and the average for the first and second lists: $\mathrm{T} 3-[(\mathrm{T} 2+\mathrm{T} 1) / 2]$. 
Number-letter task (Rogers \& Monsell, 1995): Participants had to switch between processing consonants and vowels. The shift cost was calculated in the same way as in the plus-minus test: $\mathrm{T} 3-[(\mathrm{T} 2+\mathrm{T} 1) / 2]$.

\section{Updating tasks:}

$N$-back task: Participants had to remember and update in memory only the last three letters said by the experimenter to decide whether each new one was the same as one of the three previous letters. The score was the number of correct answers (hits and correct rejections).

Self-Ordered Pointing Task (Petrides \& Milner, 1982): Participants had to update in memory the drawings they chose, in order not to choose them anymore. The score was the number of different drawings selected.

\section{Inhibition tasks:}

Stroop color word task (SCWT, Stroop 1935), card version: Participants had to inhibit word reading in order to name the color of the ink used for words depicting colors. To reduce the potential bias of patients' cognitive slowing, we used the interference score proposed by (Li \& Bosman, 1996): (Baseline - color word)/Baseline.

Hayling sentence Completion Test (HSCT, Burgess \& Shallice 1996): Participants had to inhibit the final word of sentences and say aloud a word that was not linked in any way with either the sentence or final word. The scores were the time taken to complete Part B and the number of errors in Part B.

\section{Access tasks:}

Verbal fluency: Participants had to say aloud as many words as they could according to a phonemic or semantic rule. Two verbal fluency tasks were assessed, namely phonemic fluency 
(Letter P) and semantic fluency (category "animals"). The score was the number of correct words in 60 seconds.

\section{Processing speed tasks:}

Digit copying test (Weschsler, 1989): Participants had to write down the digit matching a number according to a key. The score was the number of items correctly reported in 30 seconds. This time limit was chosen to reduce the impact of executive abilities and memory on performance (Knowles et al., 2015).

Letter comparison test: On a sheet of paper displaying pairs of $\mathrm{X}$ and $\mathrm{O}$, participants had to decide whether each pair was identical or different and to tick the corresponding box. The score was the number of correct items in 30 seconds.

\section{Data analyses}

Data used in this article are available at: https://osf.io/ebn5a/

Not all of the participants completed all the tests: 5 failed to complete the plus minus test $(4 \%)$, 1 the n-back test $(0.8 \%)$, and 10 the HSCT $(8 \%)$. The missing data were replaced using Multiple Imputation by Chained Equations (Azur et al., 2011). See Thuaire et al., (2020) for more details. Z-scores were computed for each task, based on mean and standard deviation of all participants, after which the means were calculated between the two tests in each of the four executive domains (shifting, updating, inhibition and access) and PS, to create a composite index for these cognitive abilities ${ }^{1}$.

All analyses were run on SPSS Statistics 25 (IBM Corp, 2017), running the PROCESS script to test the mediation (Hayes, 2018). Mediation signifies that the effect of an independent

\footnotetext{
${ }^{1}$ For the inhibition score, we first computed a Z-score for HSCT which included time and errors before computing the inhibition score which included HSCT and SCWT, in order to give equal weight to both tests in the index. Where necessary, Z-scores were re-coded, so that a high score reflected better performance.
} 
variable (IV) on a dependent variable (DV) is at least partly driven by a mediator (M). Several effects are calculated by means of regression analyses: $(a)$ is the effect of the IV on $\mathrm{M} ;(b)$ is the effect of M on the DV when controlling for the effect of the IV; $(c)$ is the total effect of the IV on the DV and is the sum of a direct effect $\left(c^{\prime}\right)$ of the IV on the DV and an indirect effect $(a \times b)$ which is the effect of the IV on the DV through M. As regression analyses cannot test the significance of the indirect effect $\left(\begin{array}{lll}a & x & b\end{array}\right)$, the latter is tested using a bias-corrected bootstrapping approach $(n=5,000$ bootstrap samples (Preacher \& Hayes, 2008)). Thus, if zero is not in the $95 \%$ confidence interval, we can conclude that the indirect effect is significantly different from zero. Moderated mediation means that a moderator (W) affects at least one path of the mediation relation. The effect of one variable on another may therefore be different according to the value of the moderator. Group $(0=$ Comparison participants, $1=$ Schizophrenia patients) was the IV, PS was the mediator, age was the moderator, and the four specific EFs were entered as DVs in separate analyses. Thus, the total effect is the effect of schizophrenia on a specific EF without taking into account a possible effect of PS. The direct effect is the effect of schizophrenia on a specific EF after controlling for the effect of PS, and the indirect effect is the effect of PS on a specific EF after controlling for the effect of schizophrenia. Unstandardized coefficients (B) are reported in the analyses.

\section{Results:}

Table 2 presents means and standard deviations on the five indices for schizophrenia patients and healthy comparisons participants.

Table S1 presents intercorrelations among all study variables. All variables were significantly correlated with each other, except Group with Age, Group with Inhibition and Age with Access. 
Figure 1 shows the results of the mediation analyses about the effect of schizophrenia on the four specific EFs through PS. Path (a) indicates that schizophrenia had a strong negative effect on PS. Path $(b)$ shows that higher PS increases performance in the four EFs. Mediation $(a \times b)$ was significant for the four EFs, indicating that PS mediated the four EFs. Total effects of schizophrenia on EFs $(c)$ were significant for shifting, updating and access, whereas direct effects of schizophrenia controlling for PS (c') only remained significant for updating and access.

\section{Moderated mediation analyses}

Moderation on a mediation model may be present in 3 paths: on the effect of the IV on M (path $a$ ), on the effect of M on the DV when controlling for the effect of the IV (path $b$ ), and the direct effect of the IV on the DV (path c'). However, as, despite a significant deleterious effect of age on PS $(\mathrm{B}=-.029, p<.001)$, there was no moderation effect of age on path $a(\mathrm{~B}=-.010$, $p=.197$ ), further analyses focus only on paths $b$ and $c^{\prime}$. Figure 2 shows the significant moderation effects of age on the mediation of the effect of schizophrenia on shifting (Panel A), updating (Panel B) and Access (Panel C) through PS. As may be seen in Figure 2, age moderated the mediation of schizophrenia on three out of the four EFs, but in different ways.

Moderation by age of the mediation by speed of the group effect on shifting:

Conditional process analyses using PROCESS macro revealed that only path $b$ was significantly moderated by age $(\mathrm{B}=.011, p=.002)$. Thus, the effect of PS on shifting abilities is moderated by age in such a way that the effect of speed on shifting is greater in older participants. Therefore, schizophrenia patients, whose PS is slower, are more affected by age when it comes 
to shifting abilities. Figure S1 shows the effects of age on shifting as a function of participants' PS.

Moderation by age of the mediation by speed of the group effect on updating:

PROCESS showed that both paths $b(\mathrm{~B}=-.011, p=.045)$ and $c^{\prime}(\mathrm{B}=-.022, p=.030)$ were significantly moderated by age. Thus, concerning path $b$, the effect of PS on shifting abilities is less in older participants and, consequently, for schizophrenia patients, whose processing performance is lower, older patients' updating performance would be less affected than that of younger patients. However, a counterbalancing effect is observed on path $c$ ' as age increases the effect of schizophrenia on updating, leading older schizophrenia patients to record a lower updating performance. Taken together, the effects of age on paths $b$ and $c$ ' offset each other and resulted in an absence of accelerated aging in schizophrenia patients (Thuaire et al., 2020). Figure S2 shows that the direct effect of schizophrenia on updating is more negative with advancing years, whereas the indirect effect is less negative with age.

Moderation by age of the mediation by speed of the group effect on inhibition:

The analysis failed to show any moderation effect of age on paths $b(\mathrm{~B}=.005, p=.237)$ and $c^{\prime}$ ( $\mathrm{B}=-.006, p=.403)$. Thus, the mediation by PS of the effect of schizophrenia on inhibition is not moderated by age.

Moderation by age of the mediation by speed of the group effect on access:

PROCESS analysis revealed a significant moderation effect on path $c^{\prime}(\mathrm{B}=-.016, p=.045)$. Thus, as shown in Figure S3, age moderated the direct effect of schizophrenia on access in a way that slowed the increase in schizophrenia patients' access performance with age.

\section{Discussion:}


The first aim of this study was to test the mediating role of PS on the effect of schizophrenia with respect to the four specific EFs, namely shifting, updating, inhibition and access. The second aim was to determine how age affected this mediation as a function of the four specific EFs.

Concerning the first goal, our results confirm the widely observed cognitive slowing in schizophrenia (Dickinson et al., 2007; Leeson et al., 2010; Mesholam-Gately et al., 2009; Neill \& Rossell, 2013; Ojeda et al., 2012; Savla et al., 2011) and the effect of PS on EFs (Rose et al., 2011; Salthouse et al., 1998). Moreover, in accordance with the hypothesis that improving PS should bring widespread benefits in other cognitive functions (Cassetta \& Goghari, 2016), PS mediates the effect of schizophrenia on EFs (Neill \& Rossell, 2013; Ojeda et al., 2012; Savla et al., 2011). This result is consistent with Salthouse's Processing Speed Theory (Salthouse, 1996) and suggests PS should be efficient at successfully executing simple cognitive operations and keeping the result available for more complex operations such as cognitive strategies. Thus, fast processing may help to bear in mind current rules for shifting tasks, to switch faster between these rules, to update memory faster so that materials are not forgotten, to inhibit prepotent responses faster in order to activate an alternative response, and to activate and use efficient strategies to access memory.

With respect more specifically to mediation strength, shifting seems to be the specific EF mediated mainly by PS as it is the only one that showed significant total and indirect effects and no direct effect. The effect of schizophrenia on shifting is thus almost entirely the consequence of cognitive slowing. These results are in line with those of other studies which assessed shifting with the Wisconsin Card Sorting Test (Ojeda et al., 2012) or D-KEFS (Neill \& Rossell, 2013; Savla et al., 2011). Our results also indicate that updating and access showed the most important total effect of schizophrenia, and both the direct and indirect effect remained significant, indicating that PS mediated most of the effect of schizophrenia on these EFs. 
Finally, the mediation effect of schizophrenia on inhibition through PS is more complicated insofar as the total effect was not significant. According to Haye's Framework and contrary to Baron and Kenny's method (Baron \& Kenny, 1986), a significant total effect is not required to test for mediation. More precisely, our result seems to be due to the opposite signs of the direct and indirect effects (Hayes, 2018). Thus, schizophrenia would seem to have a weak (and nonsignificant) positive direct effect (which is in keeping with both Baron and Kenny's and Haye's methods) on inhibition and a stronger negative indirect effect through PS. As the total effect is the sum of both direct and indirect effects (Hayes, 2018), the result is a non-significant total effect. This result warrants further research, but it is possible to speculate that if schizophrenia patients were not cognitively slowed their performances would be similar to comparison participants and even slightly better. Nevertheless, our results are in keeping with those observed with the D-KEFS in showing that PS contributed significantly to inhibition (Neill \& Rossell, 2013; Savla et al., 2011).

The second aim was to determine whether age could be a moderator of this mediation effect as a function of the four specific EFs. Our main finding is that age moderated the mediation on three out of the four EFs, namely shifting, access and updating, albeit in different ways. According to a previous study (Thuaire et al., 2020) which showed that with respect to shifting and access schizophrenia patients were more affected by age than comparison participants, we postulated that the mediation effect on these EFs would be moderated by age. Our results supported this hypothesis and contributed to furthering knowledge about how age affects these functions in schizophrenia. Thus, the effect of PS on shifting was greater in older participants, suggesting that, compared with slower participants, faster participants may benefit from age as regards shifting. Yet, schizophrenia patients whose PS was severely impaired saw their shifting performance decline with age compared to healthy subjects, a result interpreted as accelerated aging (Thuaire et al., 2020). 
With regard to access, the influence of age concerned the direct effect of schizophrenia and, as such, was independent from PS. More specifically, our results suggested that for comparison participants age was associated with an increase in access performance through the direct path, but that this was not the case for schizophrenia patients. The suggestion is therefore that it was the superior knowledge of vocabulary typical of healthy older adults (Fisk \& Sharp, 2004) which was responsible for this increase in performance in the direct path. Moreover, where both groups were concerned, age affected the indirect path in the same way, namely through a slowing of processing which in turn reduced access performance. It is our suggestion that the two paths offset each other out for comparison participants, resulting in the absence of age effects (Fisk \& Sharp, 2004), whereas for schizophrenia patients the direct path does not compensate for the indirect path. This interpretation of our results is in keeping with studies showing greater age-related decline in verbal fluency in schizophrenia patients (Kosmidis et al., 2005; Thuaire et al., 2020). It is therefore possible that schizophrenia patients did not improve their vocabulary with aging as much as comparison participants, or that they failed to use effective strategies in both fluency tasks.

Surprisingly, and contrary to our hypothesis, mediation of the effect of schizophrenia on updating by PS was also moderated by age. However, an examination of the direct and indirect effects indicated that moderation of these effects had opposite signs and thus resulted in the absence of accelerated aging with respect to updating (Thuaire et al., 2020). More precisely, moderation of the direct effect showed that schizophrenia patients were more impaired in terms of updating as they got older. Conversely, moderation of the indirect effect indicated that the influence of PS on updating decreased with age. As schizophrenia patients' PS was slower, they were less affected by age on this path, which offset the effect of the direct path. These results suggest that older participants relied less on PS to complete these updating tasks than their younger counterparts. We presume they tried to compensate for their cognitive slowing by 
relying more on other processes such as working memory capacity or cognitive strategies, even if that was not enough for them to match the performance of younger participants (Thuaire et al., 2020). Such assumptions are in line with a meta-analysis of neuroimaging studies (Turner \& Spreng, 2012), which showed that during an updating task older participants increased their recruitment of brain areas associated with learning and acquisition of cognitive strategies and cognitive control in working memory.

Finally, in keeping with our hypothesis and the fact that schizophrenia patients failed to show accelerated aging on inhibition (Thuaire et al., 2020), the mediation effect on this specific EF was not moderated by age.

These results suggest that PS should be assessed routinely during therapeutic follow-up and before including a patient in a remediation program. First, PS tasks are easy to administer and tap a central feature of the deficits in schizophrenia (Dickinson et al., 2007; González-Blanch et al., 2011). Second, since PS mediates EFs which are linked in turn to functional competences (Harvey et al., 1999; Kalache et al., 2015), evaluating it may help to target other functions for investigation and third, aging may have different effects on patients' cognition depending on their PS. Specifically, lowest performance patients may show a major deterioration in shifting performance but relatively spared updating performance.

Moreover, our results also show the importance of the choice of pharmacological treatment. Long-term benzodiazepine use seems to have negative effects on several areas of cognition, including PS, even after withdrawal (Crowe \& Stranks, 2018), and so it should be prescribed with caution. Concerning the treatment of depression, which is a comorbidity of schizophrenia, a meta-analysis showed that selective serotonin reuptake inhibitors had greater positive effects on cognition in depressed patients than the other classes of antidepressants (Prado et al., 2018). This result should be confirmed with further researches and tested in schizophrenia because it represents a possible area for improving patients' cognition. In any case, pharmacological 
treatment should be chosen and monitored so as to minimize neurocognitive side-effects, which may already be compromised by the disease process itself.

A potential implication of our results is that cognitive remediation programs should concentrate more on PS. Remediation programs targeting PS seem to be efficient (Garrido et al., 2013; Grynszpan et al., 2011; Lindenmayer et al., 2008; McGurk et al., 2007; Sartory et al., 2005; Vita et al., 2011). Thus, in light of our results showing that PS seems to underlie EFs, it is possible that increasing patients' PS would improve executive functioning (Rodríguez-sánchez et al., 2007).

This research has a number of strengths and limitations. First of all, EFs were assessed according to a validated model (Fisk \& Sharp, 2004; Miyake et al., 2000) which depicts the diversity of EFs. Thus, our results lend further weight to arguments in favor of using specific models of executive functioning to study schizophrenia (Thuaire et al., 2020) insofar as we demonstrated how age affects the specific EFs differently through PS. Then, despite the numerous studies suggesting an underlying role for PS in the executive deficit in schizophrenia (Dickinson et al., 2007; Neill \& Rossell, 2013; Ojeda et al., 2012; Raffard \& Bayard, 2012; Rodríguez-sánchez et al., 2007; Savla et al., 2011), this article is the first to test this mediation with an appropriate statistical analysis. Moreover, patients and comparison subjects were rigorously paired, one by one, for gender, age and educational status. A recent meta-analysis (Fioravanti et al., 2012) indicated that the imbalance in the number of cases, gender composition and age could artificially increase between group differences. However, we were unable to control former patients' medication or to clarify the long-term effects of medication on cognitive functioning. This may be a recurrent problem with cross-sectional studies on schizophrenia aging (Suzuki et al., 2011). Nonetheless, patients were treated in accordance with the guidelines for biological treatment of schizophrenia published by the World Federation of Societies of Biological Psychiatry (Hasan et al., 2012, 2013). They received stable doses of 
antipsychotics at least four weeks before inclusion and throughout the study, and most of the patients were administered only one antipsychotic which, presumably, would not cause excessive cognitive deficit. Moreover, pharmaceutic research is making constant progress, and differences in treatments between younger and older patients not only affect current patients but will probably continue in the future too. The life expectancy gap between schizophrenia patients and the general population (E. E. Lee et al., 2018) makes it difficult to recruit patients over the age of 70 , with the result that comparison participants were not as old as typically found in healthy aging studies. However, only longitudinal designs could overcome this limitation by keeping age pairing. Another recurrent limitation is that there is no pure measure of EFs or PS, and even symbol coding requires memory and executive functioning (Knowles et al., 2015). To reduce these biases, we aggregated two tasks for each function, and PS tasks were administered for 30 seconds to avoid the use of strategies or memory to perform them. However, it should be borne in mind that these cognitive processes are intrinsically linked, and it is still possible that, in combination with the model we tested, where PS mediates EFs, there is also a model where EFs mediate some PS performance.

Another statistical limitation concerns the use of psychometric assessment based on theory rather than statistics. However, the tests we used have a strong theoretical framework, and as cognition in schizophrenia patients differs from that of the general population it did not seem appropriate to us to calculate a PCA.

In conclusion, this article is the first to show the mediation effect of PS on specific EFs with the help of a recent method that can be used to test the mediation directly (Hayes, 2018). Moreover, we showed that age affected the specific EFs through PS in different ways. These results have theoretical and clinical implications insofar as PS may explain various cognitive deficits in schizophrenia and should be a major target area for cognitive remediation. Several research studies have demonstrated the benefits of PS training (Garrido et al., 2013; Grynszpan 
et al., 2011; Lindenmayer et al., 2008; McGurk et al., 2007; Sartory et al., 2005; Vita et al., 2011). However, there is a need for remediation programs that specifically target PS with a

437 view to defining how speed improvement transfers to other abilities (Cassetta \& Goghari, 2016). Further research could test the hypothesis of a cascade model of cognition in schizophrenia, where PS impairment affects executive functioning, which, in turn, affects other cognitive processes, quality of life, and outcome. Another avenue for future research would be to complete our knowledge about relationships between cognitive processes in schizophrenia. For example, we could measure the contribution of attention, some components of which are impaired in schizophrenia. Indeed, top-down control of selective attention would appear to be impaired in schizophrenia, but not bottom-up control (Gold et al., 2018). Lastly, our results give indications for adapting cognitive remediation to suit older schizophrenia patients (Wykes et al., 2009) given that aging has a direct and stronger effect on updating and access in schizophrenia. However, there is no increased effect of age in patients with regards to inhibition and shifting, except through PS for the latter.

Acknowledgements: This work was supported by the CNRS, INSERM, the UCA of ClermontFerrand, and Clermont-Ferrand University Hospital. The authors would like to thank Elisabeth Bacon for her useful comments on a previous version of this article, Gillian Wakenhut for her accuracy and patience with correcting our English, and three anonymous reviewers for their helpful comments on the article.

Financial support: This project is co-funded by the European Union in the context of the European Regional Development Fund (ERDF) [Grant number AV0017611].

Conflicts of interest: None 
Ethical standards: The authors assert that all procedures contributing to this work comply with the ethical standards of the relevant national and institutional committees on human experimentation and with the Helsinki Declaration of 1975, as revised in 2008.

\section{References}

Albinet, C. T., Boucard, G., Bouquet, C. A., \& Audiffren, M. (2012). Processing speed and executive functions in cognitive aging: How to disentangle their mutual relationship? Brain and Cognition, 79(1), 1-11. https://doi.org/10.1016/j.bandc.2012.02.001

Azur, M. J., Stuart, E. A., Frangakis, C., \& Leaf, P. J. (2011). Multiple Imputation by Chained Equations: What is it and how does it work? International Journal of Methods in Psychiatric Research, 20(1), 40-49. https://doi.org/10.1002/mpr.329.Multiple

Baron, R. M., \& Kenny, D. a. (1986). The Moderator-Mediator Variable Distinction in Social The Moderator-Mediator Variable Distinction in Social Psychological Research: Conceptual, Strategic, and Statistical Considerations. Journal of Personality and Social Psychology, 51(6), 1173-1182. https://doi.org/10.1037/0022-3514.51.6.1173

Bowie, C. R., Reichenberg, A., McClure, M. M., Leung, W. L., \& Harvey, P. D. (2008). Ageassociated differences in cognitive performance in older community dwelling schizophrenia patients: Differential sensitivity of clinical neuropsychological and experimental information processing tests. Schizophrenia Research, 106(1), 50-58. https://doi.org/10.1016/j.schres.2007.10.026

Burgess, P. W., \& Shallice, T. (1996). Response suppression, Initiation and strategy use following frontal lobe lesions. Neuropsychologia, 34(4), 263-272. https://doi.org/10.1016/0028-3932(95)00104-2 
Cassetta, B. D., \& Goghari, V. M. (2016). Working memory and processing speed training in schizophrenia: Study protocol for a randomized controlled trial. Trials, 17(1), 1-16. https://doi.org/10.1186/s13063-016-1188-5

Chan, R. C. K., Chen, E. Y. H., \& Law, C. W. (2006). Specific executive dysfunction in patients with first-episode medication-naïve schizophrenia. Schizophrenia Research, 82(1), 51-64. https://doi.org/10.1016/j.schres.2005.09.020

Chan, R. C. K., Huang, J., Guo, L., Cao, X., Hong, X., \& Gao, Z. (2010). Executive control in schizophrenia in task involving semantic inhibition and working memory. Psychiatry Research, 179(3), 259-266. https://doi.org/10.1016/j.psychres.2009.07.014

Cohen, C., Vahia, I., Reyes, P., Diwan, S., Bankole, A., Palekar, N., Kehn, M., \& Ramirez, P. (2008). Schizophrenia in Later Life : Clinical Symptoms and Social Well-being. Psychiatric Services, 59(3), 232-234. https://doi.org/10.1176/ps.2008.59.3.232

Cona, G., Arcara, G., Amodio, P., Schiff, S., \& Bisiacchi, P. S. (2013). Does executive control really play a crucial role in explaining age-related cognitive and neural differences. Neuropsychology, 27(3), 378-389. https://doi.org/10.1037/a0032708

Crowe, S. F., \& Stranks, E. K. (2018). The Residual Medium and Long-term Cognitive Effects of Benzodiazepine Use: An Updated Meta-analysis. Archives of Clinical Neuropsychology, 33(7), 901-911. https://doi.org/10.1093/arclin/acx120

Dickinson, D., Ramsey, M. E., \& Gold, J. M. (2007). Overlooking the Obvious: A Metaanalytic Comparison of Digit Symbol Coding Tasks and Other Cognitive Measures in Schizophrenia. Archives of General Psychiatry, 64(5), 532. https://doi.org/10.1001/archpsyc.64.5.532

Donohoe, G., Corvin, A., \& Robertson, I. H. (2006). Evidence that specific executive functions predict symptom variance among schizophrenia patients with a predominantly negative symptom profile. Cognitive Neuropsychiatry, 11(1), 13-32. 

https://doi.org/10.1080/13546800444000155

Fioravanti, M., Bianchi, V., \& Cinti, M. E. (2012). Cognitive deficits in schizophrenia: an updated metanalysis of the scientific evidence. BMC Psychiatry, 12(64), 1471-244. https://doi.org/10.1186/1471-244X-12-64

Fisk, J. E., \& Sharp, C. A. (2004). Age-related impairment in executive functioning: Updating, inhibition, shifting, and access. Journal of Clinical and Experimental Neuropsychology, 26(7), 874-890. https://doi.org/10.1080/13803390490510680

Fucetola, R., Seidman, L. J., Kremen, W. S., Faraone, S. V., Goldstein, J. M., \& Tsuang, M. T. (2000). Age and neuropsychologic function in schizophrenia: A decline in executive abilities beyond that observed in healthy volunteers. Biological Psychiatry, 48(2), $137-$ 146. https://doi.org/10.1016/S0006-3223(00)00240-7

Garrido, G., Barrios, M., Penadés, R., Enríquez, M., Garolera, M., Aragay, N., Pajares, M., Vallès, V., Delgado, L., Alberni, J., Faixa, C., \& Vendrell, J. M. (2013). Computerassisted cognitive remediation therapy: Cognition, self-esteem and quality of life in schizophrenia. Schizophrenia Research, 150(2-3), 563-569. https://doi.org/10.1016/j.schres.2013.08.025

Gold, J. M., Robinson, B., Leonard, C. J., Hahn, B., Chen, S., McMahon, R. P., \& Luck, S. J. (2018). Selective attention, working memory, and executive function as potential independent sources of cognitive dysfunction in schizophrenia. Schizophrenia Bulletin, 44(6), 1227-1234. https://doi.org/10.1093/schbul/sbx155

González-Blanch, C., Pérez-Iglesias, R., Rodríguez-Sánchez, J. M., Pardo-García, G., Martínez-García, O., Vázquez-Barquero, J. L., \& Crespo-Facorro, B. (2011). A digit symbol coding task as a screening instrument for cognitive impairment in first-episode psychosis. Archives of Clinical Neuropsychology, 26(1), 48-58. https://doi.org/10.1093/arclin/acq086 
Grynszpan, O., Perbal, S., Pelissolo, A., Fossati, P., Jouvent, R., Dubal, S., \& Perez-Diaz, F. (2011). Efficacy and specificity of computer-assisted cognitive remediation in schizophrenia: A meta-analytical study. Psychological Medicine, 41(1), 163-173. https://doi.org/10.1017/S0033291710000607

Harvey, P. D., Parrella, M., White, L., Mohs, R. C., \& Davis, K. L. (1999). Convergence of cognitive and functional decline in poor outcome schizophrenia. Schizophrenia Research, 35, 77-84.

Hasan, A., Falkai, P., Wobrock, T., Lieberman, J., Glenthoj, B., Gattaz, W. F., Thibaut, F., \& Möller, H. J. (2012). World Federation of Societies of Biological Psychiatry (WFSBP) Guidelines for Biological Treatment of Schizophrenia, Part 1: Update 2012 on the acute treatment of schizophrenia and the management of treatment resistance. World Journal of Biological Psychiatry, 13(5), 318-378. https://doi.org/10.3109/15622975.2012.696143

Hasan, A., Falkai, P., Wobrock, T., Lieberman, J., Glenthoj, B., Gattaz, W. F., Thibaut, F., \& Möller, H. J. (2013). World Federation of Societies of Biological Psychiatry (WFSBP) Guidelines for Biological Treatment of Schizophrenia, Part 2: Update 2012 on the longterm treatment of schizophrenia and management of antipsychotic-induced side effects. World Journal of Biological Psychiatry, 14(1), 2-44. https://doi.org/10.3109/15622975.2012.739708

Hayes, A. F. (2018). Introduction to Mediation, Moderation and Conditional Process Analysis: A Regression-Based Approach. Second Edition. (Guilford P).

Heinrichs, R. W., \& Zakzanis, K. K. (1998). Neurocognitive deficit in schizophrenia: a quantitative review of the evidence. Neuropsychology, 12(3), 426-445. https://doi.org/10.1037/0894-4105.12.3.426

Herold, C. J., Schmid, L. A., Lässer, M. M., Seidl, U., \& Schröder, J. (2017). Cognitive 
Performance in Patients with Chronic Schizophrenia Across the Lifespan. GeroPsych, 30(1), 35-44. https://doi.org/10.1024/1662-9647/a000164

IBM Corp. (2017). IBM SPSS Statistics for Windows, Version 25.0. IBM Corp.

Irani, F., Kalkstein, S., Moberg, E. A., \& Moberg, P. J. (2011). Neuropsychological performance in older patients with schizophrenia: A meta-analysis of cross-sectional and longitudinal studies. Schizophrenia Bulletin, 37(6), 1318-1326. https://doi.org/10.1093/schbul/sbq057

Jersild, A. T. (1927). Mental set and shift. Archives of Psychology, 14(Whole No 89).

Jurado, M. B., \& Rosselli, M. (2007). The elusive nature of executive functions: A review of our current understanding. Neuropsychology Review, 17(3), 213-233. https://doi.org/10.1007/s11065-007-9040-z

Kalache, S. M., Mulsant, B. H., Davies, S. J. C., Liu, A. Y., Voineskos, A. N., Butters, M. A., Miranda, D., Menon, M., Kern, R. S., \& Rajji, T. K. (2015). The Impact of Aging, Cognition, and Symptoms on Functional Competence in Individuals with Schizophrenia Across the Lifespan. Schizophrenia Bulletin, 41(2), 374-381. https://doi.org/10.1093/schbul/sbu114

Kay, S. R., Fiszbein, A., \& Opler, L. A. (1987). The Positive and Negative Syndrome Scale (PANSS) for Schizophrenia. Schizophrenia Bulletin, 13(2), 261-276. https://doi.org/10.1093/schbul/13.2.261

Knowles, E. E. M., Weiser, M., David, A. S., Glahn, D. C., Davidson, M., \& Reichenberg, A. (2015). The Puzzle of Processing Speed, Memory, and Executive Function Impairments in Schizophrenia: Fitting the Pieces Together. Biological Psychiatry, 78(11), 786-793. https://doi.org/10.1016/j.biopsych.2015.01.018

Kosmidis, M. H., Bozikas, V. P., Vlahou, C. H., Kiosseoglou, G., Giaglis, G., \& Karavatos, A. (2005). Verbal fluency in institutionalized patients with schizophrenia: Age-related 
performance decline. Psychiatry Research, 134(3), 233-240.

$$
\text { https://doi.org/10.1016/j.psychres.2005.02.003 }
$$

Laurenson, C., Gorwood, P., Orsat, M., Lhuillier, J. P., Le Gall, D., \& Richard-Devantoy, S. (2015). Cognitive control and schizophrenia: The greatest reliability of the Stroop task. Psychiatry Research, 227(1), 10-16. https://doi.org/10.1016/j.psychres.2015.03.004

Lee, E. E., Liu, J., Tu, X., Palmer, B. W., Eyler, L. T., \& Jeste, D. V. (2018). A widening longevity gap between people with schizophrenia and general population: A literature review and call for action. Schizophrenia Research, 196, 9-13. https://doi.org/10.1016/j.schres.2017.09.005

Lee, T., Crawford, J. D., Henry, J. D., Trollor, J. N., Kochan, N. A., Wright, M. J., Ames, D., Brodaty, H., \& Sachdev, P. S. (2012). Mediating effects of processing speed and executive functions in age-related differences in episodic memory performance: A crossvalidation study. Neuropsychology, 26(6), 776-784. https://doi.org/10.1037/a0030053

Leeson, V. C., Barnes, T. R. E., Harrison, M., Matheson, E., Harrison, I., Mutsatsa, S. H., Ron, M. A., \& Joyce, E. M. (2010). The relationship between IQ, memory, executive function, and processing speed in recent-onset psychosis: 1-year stability and clinical outcome. Schizophrenia Bulletin, 36(2), 400-409. https://doi.org/10.1093/schbul/sbn100

Li, K. Z. H., \& Bosman, E. A. (1996). Age Differences in Stroop-Like Interference as a Function of Semantic Relatedness. Aging, Neuropsychology, and Cognition, 3(4), 272284.

Lindenmayer, J.-P., McGurk, S. R., Mueser, K. T., Khan, A., Wance, D., Hoffman, L., Wolfe, R., \& Xie, H. (2008). A Randomized Controlled Trial of Cognitive Remediation Among Inpatients With Persistent Mental Illness. Psychiatric Services, 59(3), 241-247. https://doi.org/10.1176/ps.2008.59.3.241

Loewenstein, D. A., Czaja, S. J., Bowie, C. R., \& Harvey, P. D. (2012). Age-associated 

differences in cognitive performance in older patients with schizophrenia: A comparison with healthy older adults. American Journal of Geriatric Psychiatry, 20(1), 29-40. https://doi.org/10.1097/JGP.0b013e31823bc08c

Luria, A. R. (1966). Higher Cortical Functions in Man. Basic Book.

McClure, M. M., Bowie, C. R., Patterson, T. L., Heaton, R. K., Weaver, C., Anderson, H., \& Harvey, P. D. (2007). Correlations of functional capacity and neuropsychological performance in older patients with schizophrenia: Evidence for specificity of relationships? Schizophrenia Research, 89(1-3), 330-338. https://doi.org/10.1016/j.schres.2006.07.024

McGurk, S. R., Twamley, E. W., Sitzer, D. I., McHugo, G. J., \& Mueser, K. T. (2007). A Meta-Analysis of Cognitive Remediation in Schizophrenia. American Journal of Psychiatry, 164(12), 1791-1802. https://doi.org/10.1176/appi.ajp.2007.07060906.A

Meier, M. H., Caspi, A., Reichenberg, A., Keefe, R. S. E., Fisher, H. L., Harrington, H., Houts, R., Poulton, R., \& Moffitt, T. E. (2014). Neuropsychological decline in schizophrenia from the premorbid to the postonset period: Evidence from a populationrepresentative longitudinal study. American Journal of Psychiatry, 171(1), 91-101. https://doi.org/10.1176/appi.ajp.2013.12111438

Mesholam-Gately, R. I., Giuliano, A. J., Goff, K. P., Faraone, S. V., \& Seidman, L. J. (2009). Neurocognition in First-Episode Schizophrenia: A Meta-Analytic Review. Neuropsychology, 23(3), 315-336. https://doi.org/10.1037/a0014708

Miyake, A., Friedman, N. P., Emerson, M. J., Witzki, A. H., Howerter, A., \& Wager, T. D. (2000). The Unity and Diversity of Executive Functions and Their Contributions to Complex "Frontal Lobe" Tasks: A Latent Variable Analysis. Cognitive Psychology, 41(1), 49-100. https://doi.org/10.1006/cogp.1999.0734

Neill, E., \& Rossell, S. L. (2013). Executive functioning in schizophrenia: The result of 

impairments in lower order cognitive skills? Schizophrenia Research, 150(1), 76-80. https://doi.org/10.1016/j.schres.2013.07.034

Ojeda, N., Peña, J., Schretlen, D. J., Sánchez, P., Aretouli, E., Elizagárate, E., Ezcurra, J., \& Gutiérrez, M. (2012). Hierarchical structure of the cognitive processes in schizophrenia: The fundamental role of processing speed. Schizophrenia Research, 135(1-3), 72-78. https://doi.org/10.1016/j.schres.2011.12.004

Penadés, R., Catalán, R., Puig, O., Masana, G., Pujol, N., Navarro, V., Guarch, J., \& Gastó, C. (2010). Executive function needs to be targeted to improve social functioning with Cognitive Remediation Therapy (CRT) in schizophrenia. Psychiatry Research, 177(1-2), 41-45. https://doi.org/10.1016/j.psychres.2009.01.032

Petrides, M., \& Milner, B. (1982). Deficits on subject-ordered tasks after frontal- and temporal-lobe lesions in man. Neuropsychologia, 20(3), 249-262.

Prado, C. E., Watt, S., \& Crowe, S. F. (2018). A meta-analysis of the effects of antidepressants on cognitive functioning in depressed and non-depressed samples. Neuropsychology Review, 28(1), 32-72. https://doi.org/10.1007/s11065-018-9369-5

Preacher, K. J., \& Hayes, A. F. (2008). Asymptotic and resampling strategies for assessing and comparing indirect effects in multiple mediator models. Behavior Research Methods, 40(3), 879-891. https://doi.org/10.3758/BRM.40.3.879

Rabanea-Souza, T., Akiba, H. T., Berberian, A. A., Bressan, R. A., Dias, Á. M., \& Lacerda, A. L. T. (2016). Neuropsychological correlates of remission in chronic schizophrenia subjects: The role of general and task-specific executive processes. Schizophrenia Research: Cognition, 3, 39-46. https://doi.org/10.1016/j.scog.2015.12.001

Raffard, S., \& Bayard, S. (2012). Understanding the executive functioning heterogeneity in schizophrenia. Brain and Cognition, 79(1), 60-69. https://doi.org/10.1016/j.bandc.2012.01.008 
Rajji, T. K., \& Mulsant, B. H. (2008). Nature and course of cognitive function in late-life schizophrenia: A systematic review. Schizophrenia Research, 102, 122-140. https://doi.org/10.1016/j.schres.2008.03.015

Reichenberg, A., \& Harvey, P. D. (2007). Neuropsychological impairments in schizophrenia: Integration of performance-based and brain imaging findings. Psychological Bulletin, 133(5), 833-858. https://doi.org/10.1037/0033-2909.134.3.382

Rodríguez-sánchez, J. M., Crespo-facorro, B., González-Blanch, C., Pérez-Iglesias, R., \& Vázquez-barquero, J. L. (2007). Cognitive dysfunction in first-episode psychosis : the processing speed hypothesis. British Journal of Psychiatry, 191(suppl 51), 107-110. https://doi.org/10.1192/bjp.191.51.s107

Rogers, R. D., \& Monsell, S. (1995). Costs of a Predictable Switch Between Simple Cognitive Tasks. Journal of Experimental Psychology: General, 124(2), 207-231. https://doi.org/10.1037/0894-4105.20.6.675

Rose, S. A., Feldman, J. F., \& Jankowski, J. J. (2011). Modeling a cascade of effects: The role of speed and executive functioning in preterm/full-term differences in academic achievement. Developmental Science, 14(5), 1161-1175. https://doi.org/10.1111/j.14677687.2011.01068.x

Rossell, S. L. (2006). Category fluency performance in patients with schizophrenia and bipolar disorder: The influence of affective categories. Schizophrenia Research, 82, 135138. https://doi.org/10.1016/j.schres.2005.10.013

Salthouse, T. A. (1996). The processing-speed theory of adult age differences in cognition. Psychological Review, 103(3), 403-428. https://doi.org/10.1037/0033-295X.103.3.403

Salthouse, T. A., Fristoe, N., McGuthry, K. E., \& Hambrick, D. Z. (1998). Relation of task switching to speed, age, and fluid intelligence. Psychology and Aging, 13(3), 445-461. https://doi.org/10.1037/0882-7974.13.3.445 
Sartory, G., Zorn, C., Groetzinger, G., \& Windgassen, K. (2005). Computerized cognitive remediation improves verbal learning and processing speed in schizophrenia. Schizophrenia Research, 75(2-3), 219-223. https://doi.org/10.1016/j.schres.2004.10.004

Savla, G. N., Twamley, E. W., Thompson, W. K., Delis, D. C., Jeste, D. V., \& Palmer, B. W. (2011). Evaluation of Specific Executive Functioning Skills and the Processes Underlying Executive Control in Schizophrenia. Journal of International Neuropsychological Society, 17(1), 14-23. https://doi.org/10.1111/j.17436109.2008.01122.x.Endothelial

Silverstein, A. B. (1982). Two-and Four-Subtest Short Forms of the Wechsler Adult Intelligence Scale-Revised. Journal of Consulting and Clinical Psychology, 50(3), 415418. https://doi.org/10.1037/0022-006x.50.3.415

Spector, A., \& Biederman, I. (1976). Mental Set and Mental Shift Revisited. American Journal of Psychology, 89(4), 669-679.

Stirling, J., White, C., Lewis, S., Hopkins, R., Tantam, D., Huddy, A., \& Montague, L. (2003). Neurocognitive function and outcome in first-episode schizophrenia: A 10-year follow-up of an epidemiological cohort. Schizophrenia Research, 65, 75-86. https://doi.org/10.1016/S0920-9964(03)00014-8

Stroop, J. R. (1935). Studies of interference in serial verbal reactions. Journal of Experimental Psychology, 18(6), 643-662. https://doi.org/10.1037/h0054651

Suzuki, H., Gen, K., \& Inoue, Y. (2011). An unblinded comparison of the clinical and cognitive effects of switching from first-generation antipsychotics to aripiprazole, perospirone or olanzapine in patients with chronic schizophrenia. Progress in NeuroPsychopharmacology and Biological Psychiatry, 35(1), 161-168. https://doi.org/10.1016/j.pnpbp.2010.10.021

Thuaire, F., Rondepierre, F., Bacon, E., Vallet, G. T., Jalenques, I., \& Izaute, M. (2020). 
Executive functions in schizophrenia aging: differential effects of age within specific executive functions. Cortex, in press. https://doi.org/10.1016/j.cortex.2019.12.003

Tolman, A. W., \& Kurtz, M. M. (2012). Neurocognitive predictors of objective and subjective quality of life in individuals with schizophrenia: A meta-analytic investigation. Schizophrenia Bulletin, 38(2), 304-315. https://doi.org/10.1093/schbul/sbq077

Turner, G. R., \& Spreng, R. N. (2012). Executive functions and neurocognitive aging: Dissociable patterns of brain activity. Neurobiology of Aging, 33(4), 826.e1-826.e13. https://doi.org/10.1016/j.neurobiolaging.2011.06.005

Verhaeghen, P., \& Cerella, J. (2002). Aging, executive control, and attention: a review of meta-analyses. Neuroscience \& Biobehavioral Reviews, 26(7), 849-857. https://doi.org/10.1016/S0149-7634(02)00071-4

Vita, A., De Peri, L., Barlati, S., Cacciani, P., Deste, G., Poli, R., Agrimi, E., Cesana, B. M., \& Sacchetti, E. (2011). Effectiveness of different modalities of cognitive remediation on symptomatological, neuropsychological, and functional outcome domains in schizophrenia: A prospective study in a real-world setting. Schizophrenia Research, 133(1-3), 223-231. https://doi.org/10.1016/j.schres.2011.08.010

Weschsler, D. A. (1989). Echelle d'intelligence de Wechsler pour adultes forme révisée WAIS-R (ECPA).

Westerhausen, R., Kompus, K., \& Hugdahl, K. (2011). Impaired cognitive inhibition in schizophrenia: A meta-analysis of the Stroop interference effect. Schizophrenia Research, 133, 172-181. https://doi.org/10.1016/j.schres.2011.08.025

Wongupparaj, P., Kumari, V., \& Morris, R. G. (2015). Executive function processes mediate the impact of working memory impairment on intelligence in schizophrenia. European Psychiatry, 30(1), 1-7. https://doi.org/10.1016/j.eurpsy.2014.06.001

Wykes, T., Reeder, C., Landau, S., Matthiasson, P., Haworth, E., \& Hutchinson, C. (2009). 
740

741

742

743

744

745

746

747

748

749

750

751

752

753

754

755

756

757 Table 1. Demographic characteristics of patients with schizophrenia and comparison
Zigmond, A. S., \& Snaith, R. P. (1983). The Hospital Anxiety and Depression Scale. Acta Psychiatrica Scandinavica, 67(6), 361-370. https://doi.org/10.1111/j.16000447.1983.tb09716.x 
participants (standard deviations shown in brackets).

\begin{tabular}{lcccc}
\hline & $\begin{array}{c}\text { Schizophrenia } \\
\text { patients } \mathrm{n}=62\end{array}$ & $\begin{array}{c}\text { Comparison } \\
\text { participants } \\
\mathrm{n}=62\end{array}$ & $t$-test & $p$ value \\
\hline Men/women & $35 / 27$ & $35 / 27$ & \\
Age (years) & $46.4(15.7)$ & $46.7(15.6)$ & 0.1 & $n s$ \\
Level of education & $11.3(2.9)$ & $11.5(2.7)$ & 0.3 & $n s$ \\
PANSS total & $68.8(18.8)$ & & & \\
$\quad$ Positive score & $14.5(5.1)$ & & & \\
$\quad$ Negative score & $18.5(7.4)$ & & & \\
$\quad$ General psychopathology & $33.9(9.4)$ & & & \\
HADS A & $7.8(3.8)$ & $5.6(3.4)$ & 3.4 & $<.001$ \\
HADS D & $6.4(3.3)$ & $3.8(2.9)$ & 4.8 & $<.001$ \\
Verbal IQ & $86.6(15.6)$ & $99.2(15.5)$ & 4.5 & $<.001$ \\
\hline
\end{tabular}

759

760

761

762

763

764

765

\begin{tabular}{lcc}
\cline { 2 - 3 } & Schizophrenia patients & Comparison participants \\
\hline Shifting & $-.302(.844)$ & $.302(.414)$ \\
Updating & $-.404(.810)$ & $.404(.661)$ \\
Inhibition & $-.058(.876)$ & $.058(.600)$ \\
Access & $-.481(.886)$ & $.481(.666)$ \\
Speed & $-.553(.891)$ & $.553(.679)$ \\
\hline
\end{tabular}
Quotient. (standard deviations shown in brackets).

Notes. PANSS= Positive And Negative Symptom Scale; HADS= Hospital Anxiety and Depression Scale; IQ= Intelligence

Table 2. Mean z-scores on the four indices of specific functions and on processing speed

Table S1. Correlations between all study variables. 


\begin{tabular}{|c|c|c|c|c|c|c|c|c|c|c|c|}
\hline & 2. & 3. & & 4. & & 5. & & 6. & & 7. & \\
\hline 1. Group & -.009 & -.416 & $* * *$ & -.483 & $* * *$ & -.078 & & -.527 & $* * *$ & -.576 & $* * *$ \\
\hline 2. Age & & -.272 & $* *$ & -.290 & $* *$ & -.473 & $* * *$ & -.131 & & -.465 & $* * *$ \\
\hline 3. Shifting & & & & .477 & $* * *$ & .394 & $* * *$ & .447 & $* * *$ & .636 & $* * *$ \\
\hline 4. Updating & & & & & & .366 & $* * *$ & .604 & $* * *$ & .617 & $* * *$ \\
\hline 5. Inhibition & & & & & & & & .299 & $* * *$ & .332 & $* * *$ \\
\hline 6. Access & & & & & & & & & & .650 & $* * *$ \\
\hline
\end{tabular}

773

7. Processing speed
774

775

Figure 2: Representation of the mediation of the effect of schizophrenia on executive

Figure 1: Mediation model for the direct and indirect effects of schizophrenia on the four specific executive functions through processing speed. Numbers associated with $a, b, c, c^{\prime}$ and $a \times b$ are unstandardized regression coefficients. $* p<.05 . * * p<.01 . * * * p<.001 . \mathrm{CI}=95 \%$ bias-corrected bootstrap confidence interval.

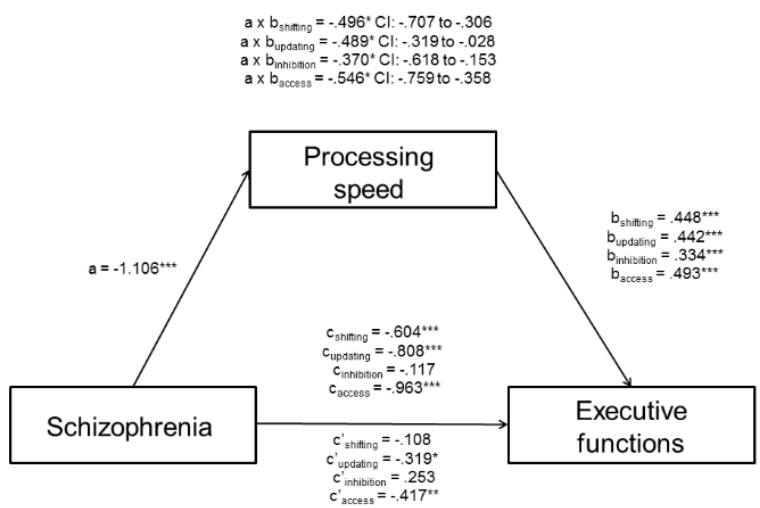

(1)

(1)

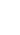



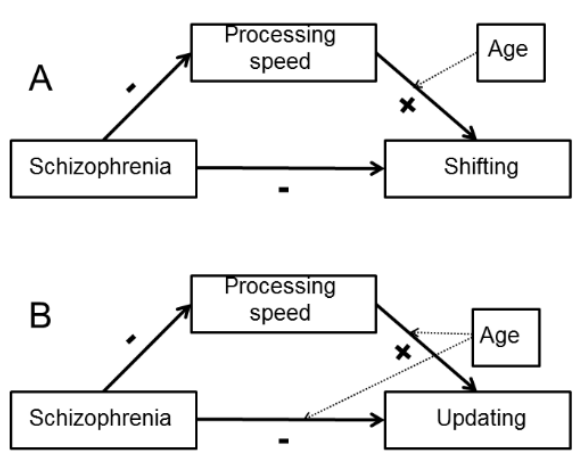

790

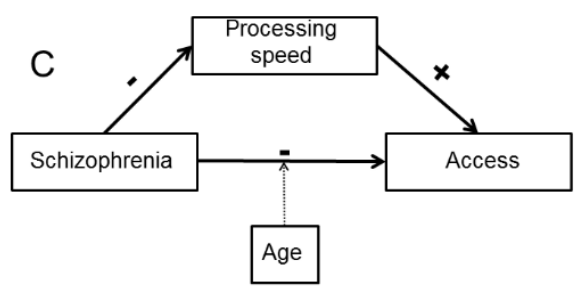

791 Figure S1: Moderation of the effect of processing speed on shifting by age.

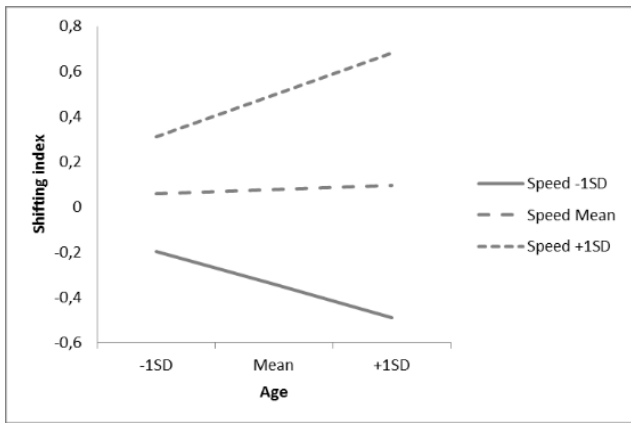

793 Figure S2: Direct and indirect effects of schizophrenia on updating as a function of participants' age.

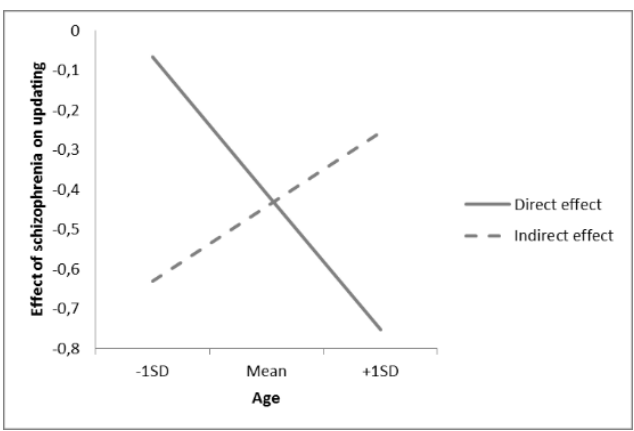

Figure S3: Moderation of the direct effect of schizophrenia on access by age. 


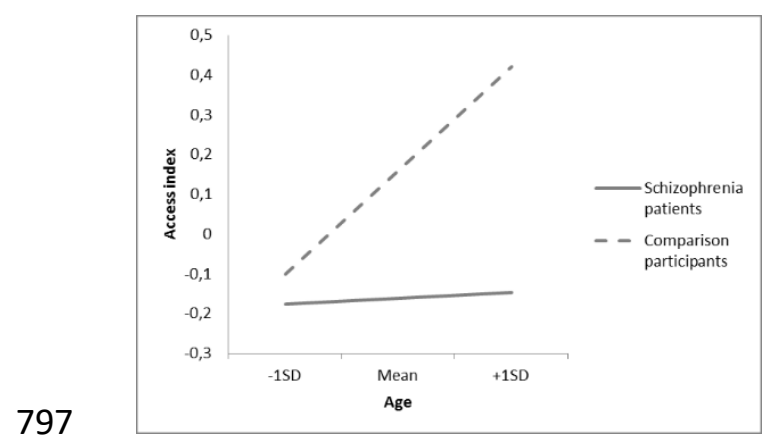

798 